\title{
Effect of Temperature on Pyrolysis Oil Using High-Density Polyethylene and Polyethylene Terephthalate Sources From Mobile Pyrolysis Plant
}

\author{
Ruktai Prurapark*, Kittwat Owjaraen, Bordin Saengphrom, Inpitcha Limthongtip and \\ Nopparat Tongam
}

Faculty of Engineering, Srinakharinwirot University, Nakhon Nayok, Thailand

OPEN ACCESS

Edited by:

Su Shiung Lam,

University of Malaysia

Terengganu, Malaysia

Reviewed by:

Reynaldo Palacios-Bereche, Federal University of $A B C$, Brazil

Rafeah Wahi,

Universiti Malaysia Sarawak, Malaysia

*Correspondence:

Ruktai Prurapark

ruktai@g.swu.ac.th

Specialty section:

This article was submitted to Process and Energy Systems Engineering, a section of the journal

Frontiers in Energy Research

Received: 09 March 2020 Accepted: 23 October 2020 Published: 27 November 2020

Citation:

Prurapark R, Owjaraen K, Saengphrom B, Limthongtip I and Tongam N (2020) Effect of Temperature on Pyrolysis Oil Using High-Density Polyethylene and Polyethylene Terephthalate Sources

From Mobile Pyrolysis Plant.

Front. Energy Res. 8:541535. doi: 10.3389/fenrg.2020.541535
This research aims to study the effect of temperature, collecting time, and condensers on properties of pyrolysis oil. The research was done be analyzing viscosity, density, proportion of pyrolysis products and performance of each condenser towers for the pyrolysis of high-density polyethylene (HDPE) and polyethylene terephthalate (PET) in the mobile pyrolysis plant. Results showed that the main product of HDPE resin was liquid, and the main product of PET resin was solid. Since the pyrolysis of PET results in mostly solid which blocked up the pipe, the analysis of pyrolysis oil would be from the use of HDPE as a raw material. The pyrolysis of HDPE resin in the amount of $100 \mathrm{~kg}$ at 400,425 , and $450^{\circ} \mathrm{C}$ produced the amount of oil $22.5,27$, and $40.5 \mathrm{~L}$, respectively. The study found that $450^{\circ} \mathrm{C}$ was the temperature that gives the highest amount of pyrolysis oil in the experiment. The viscosity was in the range of $3.287-4.850 \mathrm{cSt}$. The density was in the range of $0.668-0.740 \mathrm{~kg} / \mathrm{L}$. The viscosity and density were increased according to three factors: high pyrolysis temperature, number of condensers and longer sampling time. From the distillation at temperatures below $65,65-170,170-250$, and above $250^{\circ} \mathrm{C}$, all refined products in each temperature range had the carbon number according to their boiling points. The distillation of pyrolysis oil in this experiment provided high amount of kerosene, followed by gasoline and diesel.

Keywords: index terms-pyrolysis, high density polyethylene, polyethylene terephthalate, energy, environmental

\section{INTRODUCTION}

Energy is important to life and is one of the economic drivers. At present, Thailand has faced with energy problems because Thailand imports energy mainly oil from middle east which affects the way of life and the overall economy of the country. Therefore, energy sustainability is one of Thai society's problems that urgently need solutions. The utilization of energy from waste is an option that has been promoted by the government which has both direct and indirect benefits.

From the Pollution Control Department's pollution quantity survey in 2014, the amount of solid municipal waste in Thailand is 26.17 million tons per year. There is only $19 \%$ correct disposal, resulting in accumulated waste up to 19.9 million tons per year. There is also an amount of landfill waste accumulated more than 300 million tons and continuously increase every year. Considering the waste composition, there are generally about $18 \%$ of plastic waste, equivalent to 3.75 million tons 

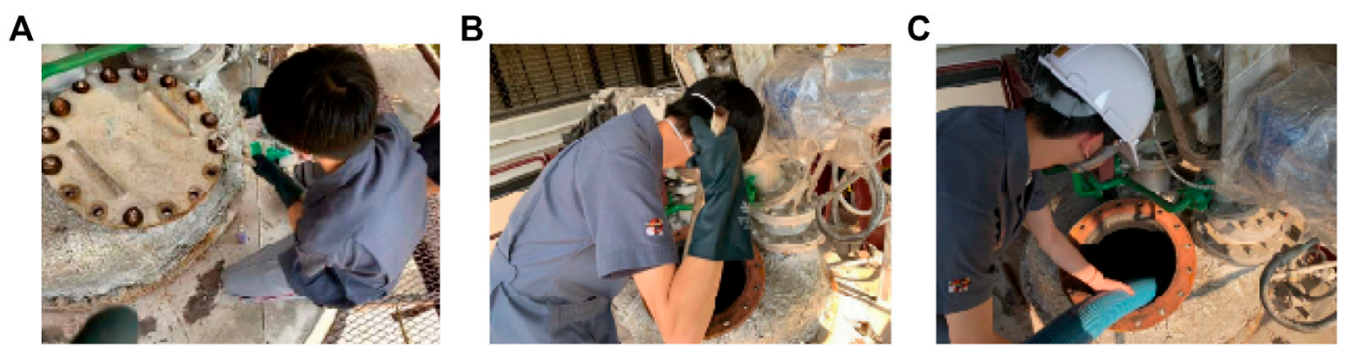

FIGURE 1 | Preparation of pyrolysis reactor (A) Opening the lid of a pyrolysis reactor (B) Using metal spade to scrape off any remaining sediments and (C) Extracting excess sediments and any remaining solid from previous operating sessions using Cyclone machine.

per year and another 25.79 million tons from accumulated waste, which can be processed into pyrolysis oil.

Pyrolysis oil is the oil obtained from biomass, however in this project we use the plastic waste for raw material due to plastic is a main municipal waste in Thailand. The processing rate is $500 \mathrm{~L}$ per ton of plastic waste and the oil produced can be used to replace fuel oil and low cycle diesel which our researchers already test in laboratory and confirmed. For this engineering project, we study the temperature of the pyrolysis process to produce oil from plastic pellets, testing the properties of oil obtained at each temperature, and increasing the purity of pyrolysis oil.

The objective of this research is to 1) study the proportion of final pyrolysis oil products in each temperature, 2) study the properties of pyrolysis oil obtained at each temperature, and 3) study the performance of each condensate tower.

\section{THEORIES AND RELATED RESEARCHES}

\section{Plastic}

Plastics are synthetic organic compounds that are used to replace certain natural materials. The plastic is divided into two types: thermoplastic and thermosetting plastics. There are many types of thermoplastics, such as high density polyethylene (HDPE) with specific gravity values of $0.941-0.965 \mathrm{~g} / \mathrm{cm}^{3}$. HDPE has a melting point temperature of about $135^{\circ} \mathrm{C}$, with a linear molecular structure. There are also many types of thermosetting plastics. Polyethylene terephthalate (PET) is the one of them.

\section{Pyrolysis Process}

The pyrolysis process is the process of decomposition of various compounds or materials with thermal decomposition at temperatures around $400-800^{\circ} \mathrm{C}$ in an oxygen-free atmosphere or contain very small amount of oxygen.

In general, the products obtained from the pyrolysis process can be divided into three types according to the condition. The primary product can be gas, liquid (which has oil-like properties) and char. The ratio of obtained products depends on the processing conditions, such as temperature, heat rate, etc. The most preferred product is liquid or oil.

\section{Oil Specifications and Testing}

There are few characteristics of the oil that can be directly tested by the instrument, such as sulfur content, viscosity values, etc. In addition, most values are measured by using certain tests that use standards to determine, such as using the standards of ASTM (American Society for Testing and Material) or IP (Institute of Petroleum), etc. The properties tested are 1) flash point 2) viscosity 3) heating value and 4) specific gravity.

\section{CHEMICALS, EQUIPMENT AND METHODS}

\section{Chemicals}

Chemicals used in this study were HDPE resin from IRPC Company Limited, PET from Thai Chin Kong Industry Corporation Limited, liquefied petroleum gas, and liquid fuel.
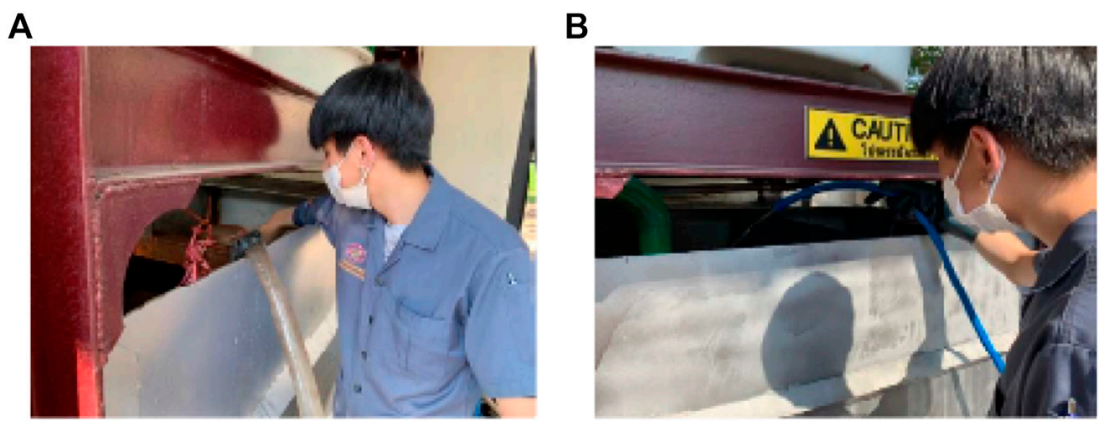

FIGURE 2 | Preparation of the coolant (A) Taking remain water out of the coolant tank and (B) Adding new water into the tank. 


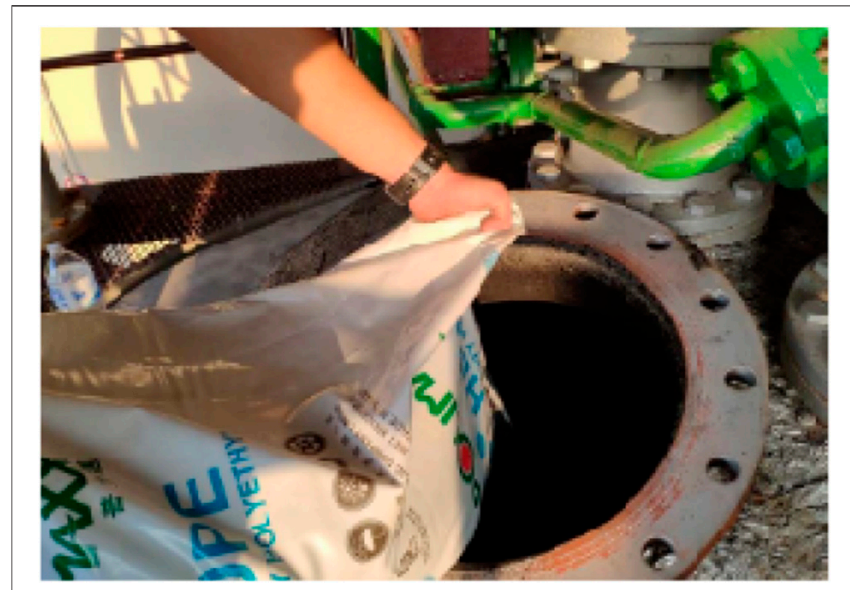

FIGURE 3 | Adding raw materials.

\section{Equipment}

Equipment used in this study were mobile pyrolysis system kit, gallon volume $4.5 \mathrm{~L}$, cyclone machine, two 12 -inch wrench, diameter $1 / 2$ inch hose ( $3 \mathrm{~m}$ long), long spade, rice sacks, Brookfield viscometer DV-I+, pure distillation unit, and 3position weighing scales.

\section{Experimental Methods \\ Preparation of Pyrolysis Reactor}

Preparation of pyrolysis reactors by cleaning the machine from sediment trapped inside. Opening the lid of the pyrolysis reactor from above with a wrench (Figure 1A), then use a long spade to scrape off the sediment trapped inside the reactor (Figure 1B). After that, use a cyclone to remove all sediment (Figure 1C).

\section{Preparation of the Coolant}

Water preparation for use in coolers by taking the remaining water out of the coolant tank Figure 2A and add the new one into the tank Figure $2 \mathrm{~B}$ to be ready to use the coolant for mobile pyrolysis systems.

\section{Adding Raw Materials}

The plastic pellets used in the experiment are fed into the pyrolysis reactor as shown in Figure 3.

\section{Collecting Pyrolysis Oil Samples}

After the pyrolysis process is complete, oil samples will be collected at the first, second, third, and fourth condensers respectively, as shown in Figure $\mathbf{4 A}$, by opening the valve of the bottom filter of each condenser, in order to bring the pyrolysis oil that is condensed at that condenser in the pyrolysis oil refining process (Figure 4B).

\section{Mobile Type Pyrolysis Equipment}

Three-dimensional model of mobile type pyrolysis equipment shown in Figures 5A,B conveying plastic waste by waste conveyor (6) into the raw material shredding machine and into (15) pyrolysis reactor heating by using (13) heating furnace to system at a temperature of $400^{\circ} \mathrm{C}$. Over time, the plastic granules will become liquid and evaporate into gas flowing into (3) gas separator to enter (1) the main condenser and enter in (1) condense the first, second, third, and fourth units and collect the oil samples at the exit of the four solid filters at the bottom of each condenser, keeping the temperature to $400^{\circ} \mathrm{C}$ as For $10 \mathrm{~min}$, then collect the oil samples again until complete three times every $10 \mathrm{~min}$. After that, increase the temperature at the reactor to 425 and $450^{\circ} \mathrm{C}$. Experimenting the same method at the temperature of $400^{\circ} \mathrm{C}$ (Figures 6 and 7).

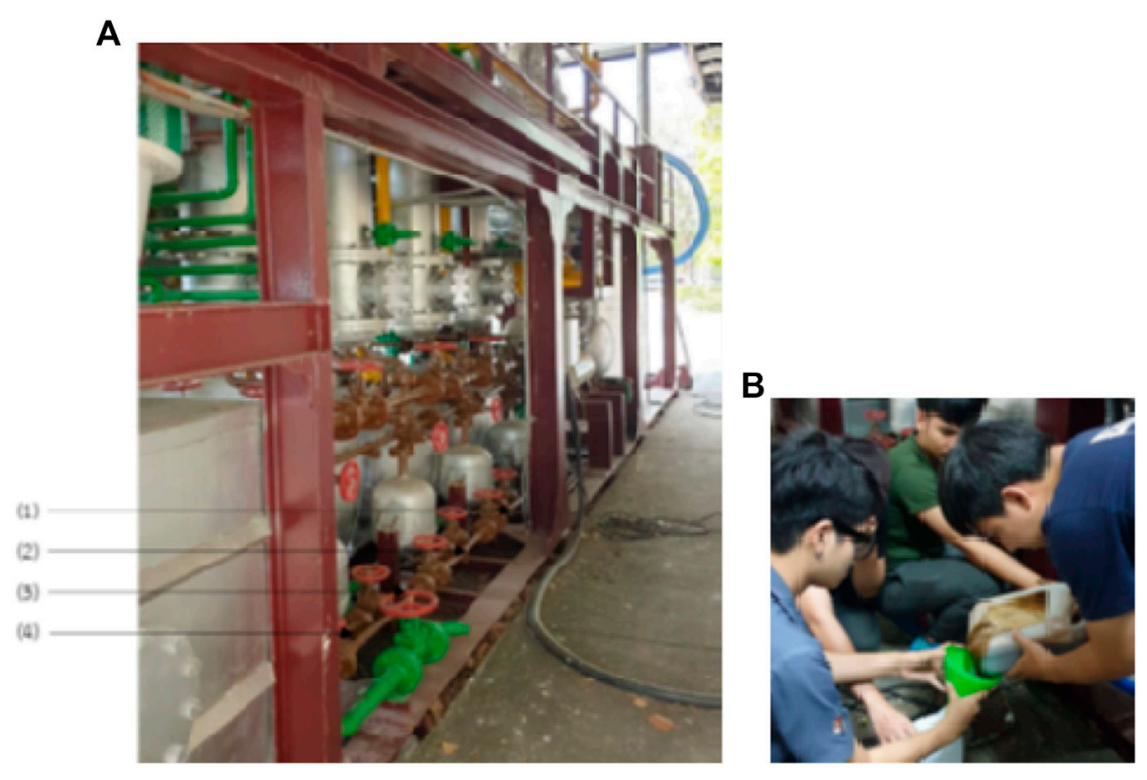

FIGURE 4 | Collecting pyrolysis oil samples (A) four collecting areas and (B) Collecting the condensed pyrolysis oil. 

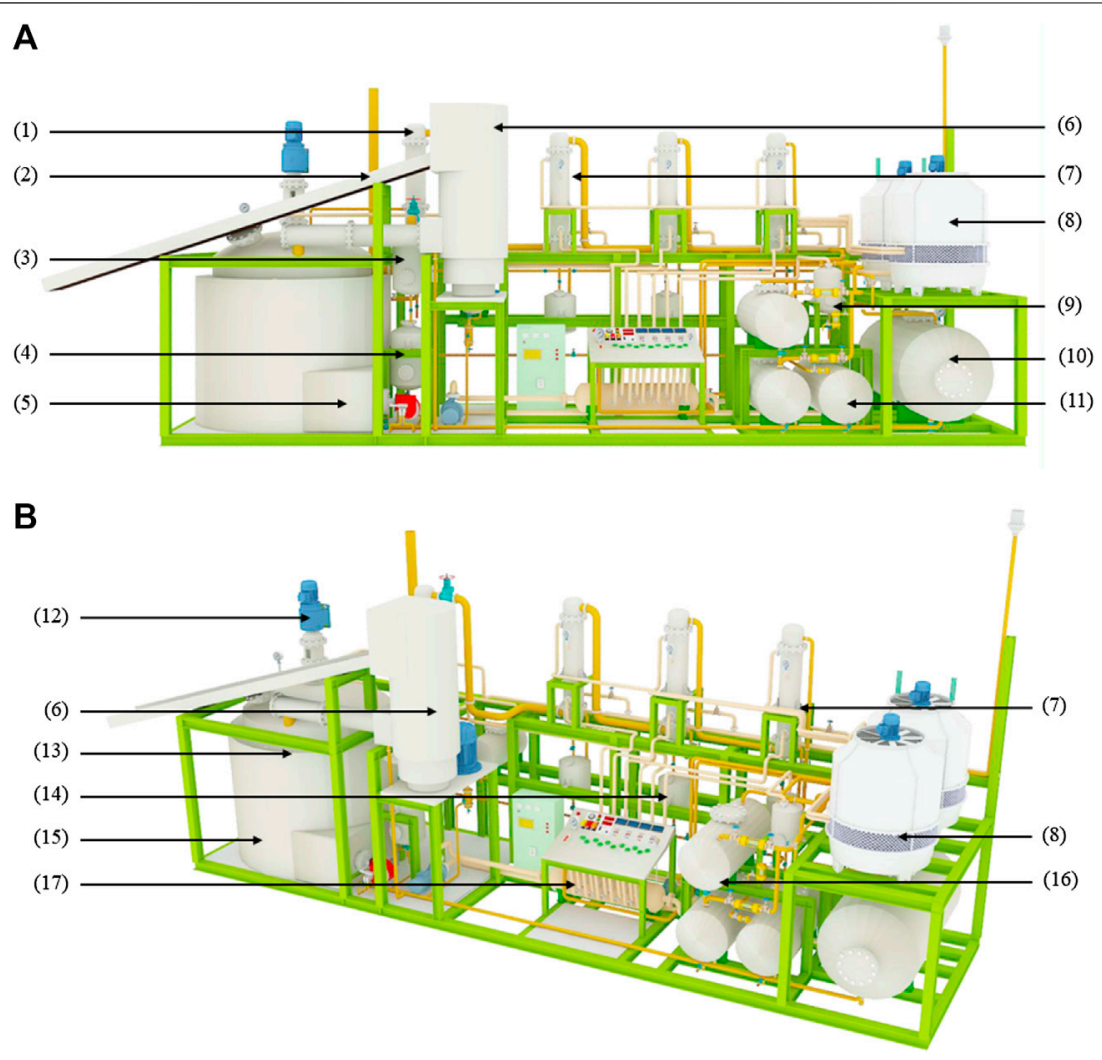

FIGURE 5 | Three-dimensional model of the mobile pyrolysis equipment set Three-dimensional model of the mobile pyrolysis equipment set when (A,B) consists of (1) Cyclone, (2) Waste conveyor belt, (3) First gas separator, (4) Gas storage tank, (5) Burner, (6) Sub-machine feeder, (7) Condenser, (8) Cooling machine, (9) Second gas separator, (10) Cooling water tank, (11) Pyrolysis oil storage tank, (12) Gear motor stirring set, (13) Kilns, (14) Product filters, (15) Reactor, (16) Pyrolysis oil storage tanks, and (17) Coolant.

\section{Analysis}

\section{Oil Refining Set}

The liquid product obtained from pyrolysis of HDPE and PET distilled by the oil distillation kit as shown in Figure 8 consists of 1) thermometer 2) three-way joints 3) round bottom bottles 4) heating furnaces 5) condensers 6) vacuum joints 7) apple shaped bottles that are distilled at low temperature ranges of lower than $65,65-170,170-250$, and over $250^{\circ} \mathrm{C}$.

\section{Viscosity Analysis}

Viscosity analysis was accomplished with Brookfield viscometer DV-I+ at $40^{\circ} \mathrm{C}$ by adding $1 \mathrm{ml}$ of sample into the sample cup and returning to the viscometer. Adjust the cone with the adjustment ring to contact the liquid surface, and adjust the rotation of the machine to 20 RPM to measure viscosity. The result was reported on screen in centipoise $(\mathrm{cP})$, then convert the unit to centistoke (cSt) from Eq. 1.

$$
\mu_{c S t}=\frac{\mu_{c P}}{\rho \times 1000}
$$

where,

$\mu_{c P}$ is the viscosity in centipoise $(\mathrm{cP})$

$\mu_{c S t}$ is the viscosity in centistoke $(\mathrm{cSt})$

$\rho$ is the density of oil sample in Gram per cubic meter $\left(\mathrm{g} / \mathrm{cm}^{3}\right)$

\section{Analysis of Hydrocarbon Compounds}

Analysis of various hydrocarbon compounds in the pyrolysis oil by fractional distillation with $300 \mathrm{ml}$ volume purity distillation equipment at temperature ranges of lower than 65, 65-170, $170-250$, and more than $250^{\circ} \mathrm{C}$. These are standard fractional distillation temperature ranges that use in normal petrochemical process which we have adapted in laboratory scale. The petrochemical products were found from this experiment.

\section{RESULTS AND DISCUSSION}

\section{Effect of Raw Materials on Products}

From the experiment, it was found that products obtained from the pyrolysis of HDPE were liquid with brown color, which is shown in Figure 9. On the other hand, the pyrolysis of PET resulted in gas and solid (Figure 10). While gas could be recycled in the process as fuel, solid blocked up the pipe resulting in the termination of process. This corresponds to the study from Williams and Slaney (2007) which stated that the pyrolysis of polyethylene, polypropylene, and polystyrene mostly yield oil products, while the pyrolysis of PET results in mostly solid 

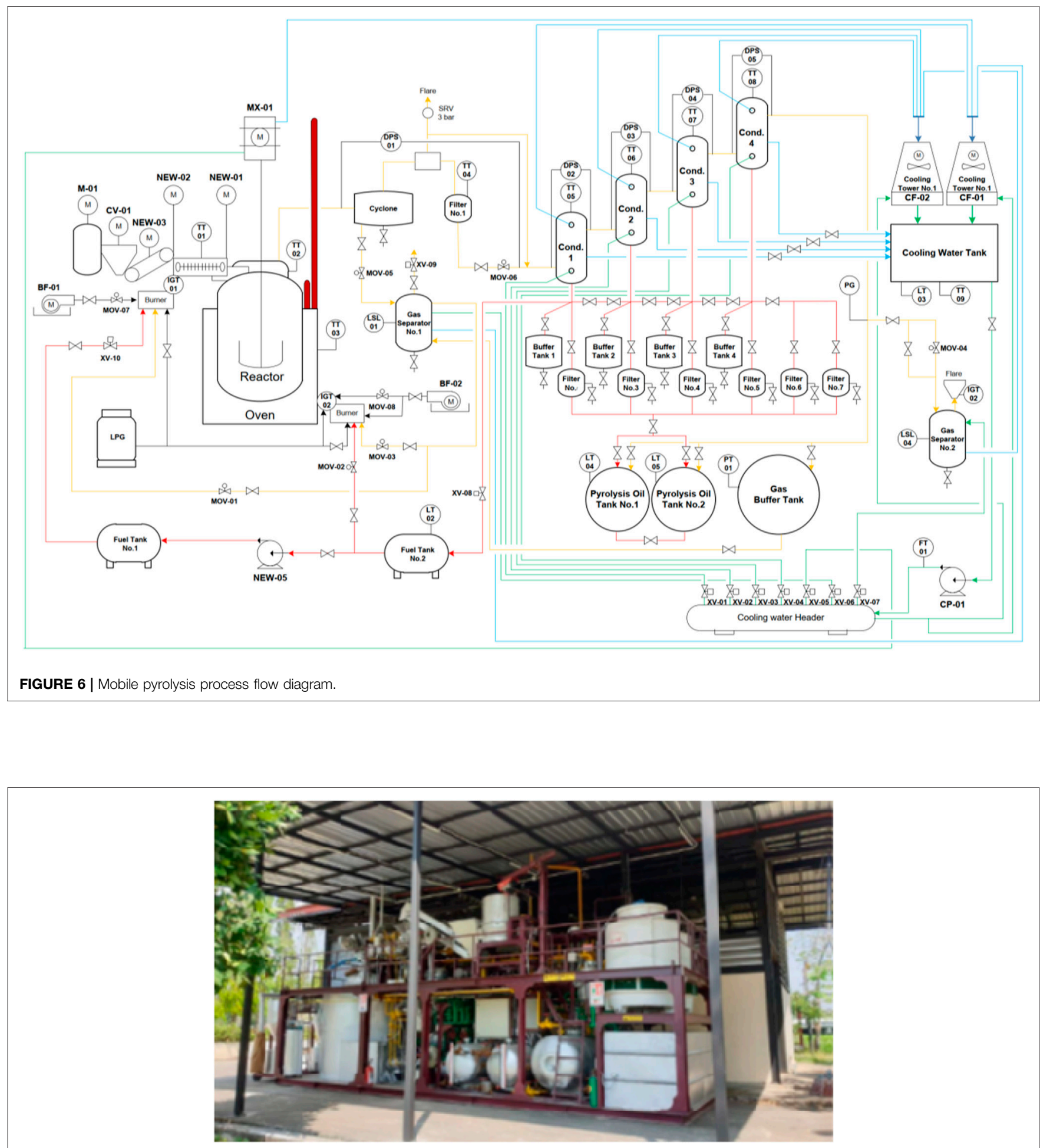

FIGURE 7 | Mobile type pyrolysis equipment set.

products. Also, Encinar and Gonzalez (2008) reported that the pyrolysis of PET yields high amount of carbon monoxide and carbon dioxide since the plastic contains high amount of oxygen.
Since the pyrolysis of PET could not produce oil, the analysis in the following section would be from the use of HDPE as a raw material only (Figure 10). 


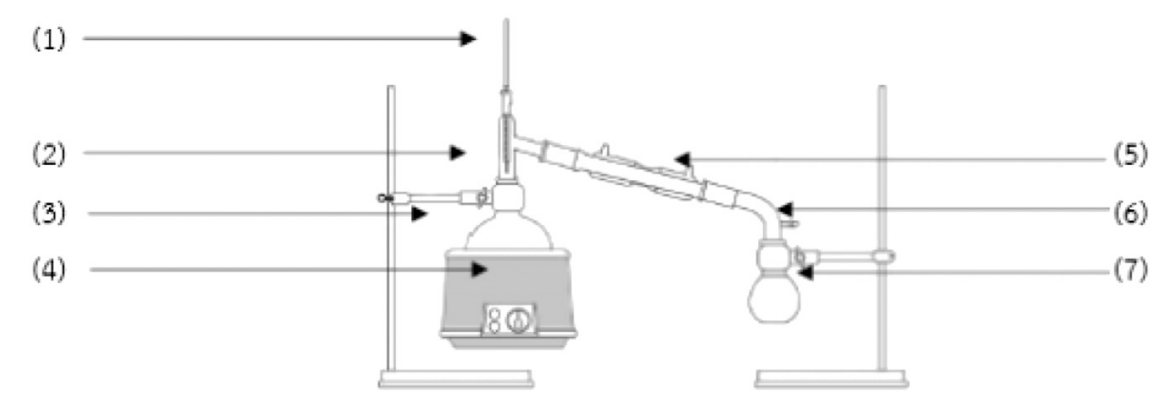

FIGURE 8| The distillation unit consists of (1) thermometer (2) three-way joint (3) round bottom bottle (4) heating furnace (5) condenser (6) vacuum coupling and (7) Erlenmeyer flask.

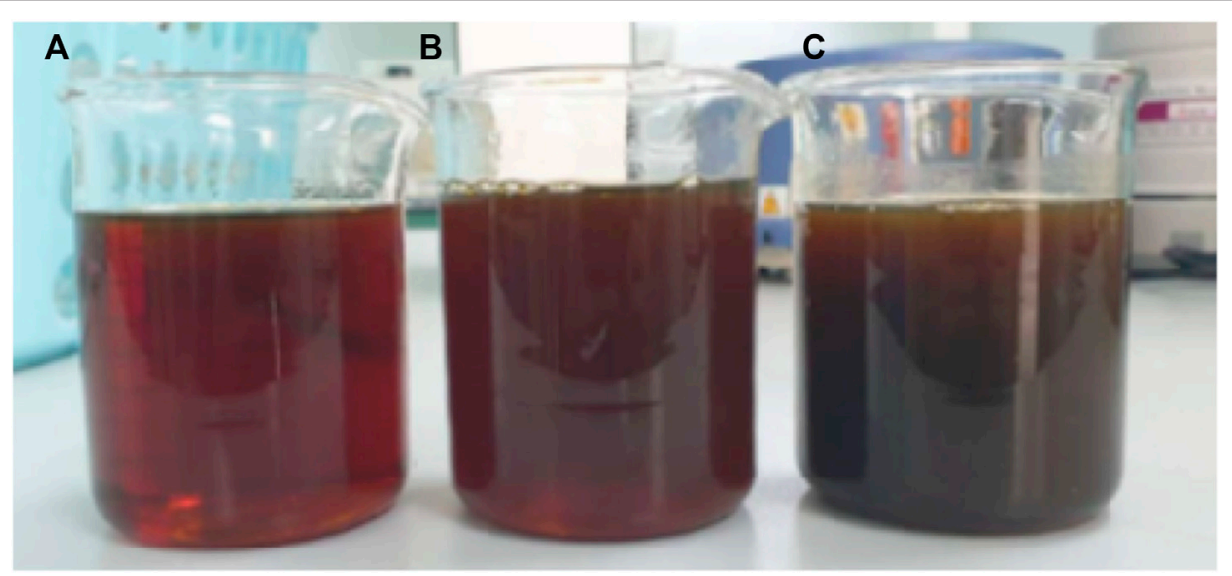

FIGURE 9| Products obtained from the pyrolysis of HDPE pellets (A) first sample collection (B) second sample collection (10 min after first collection), and (C) the third sample collection (20 min after first collection).

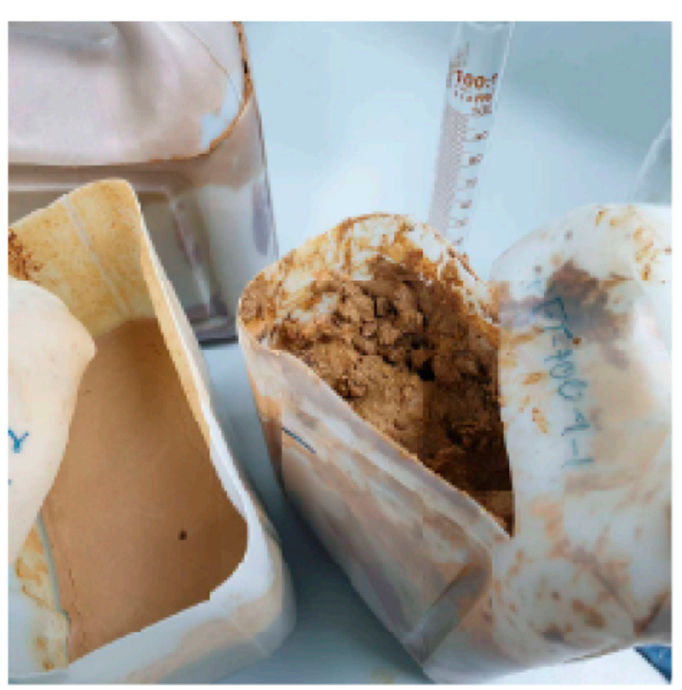

FIGURE 10 | Products obtained from the pyrolysis of PET pellets. 


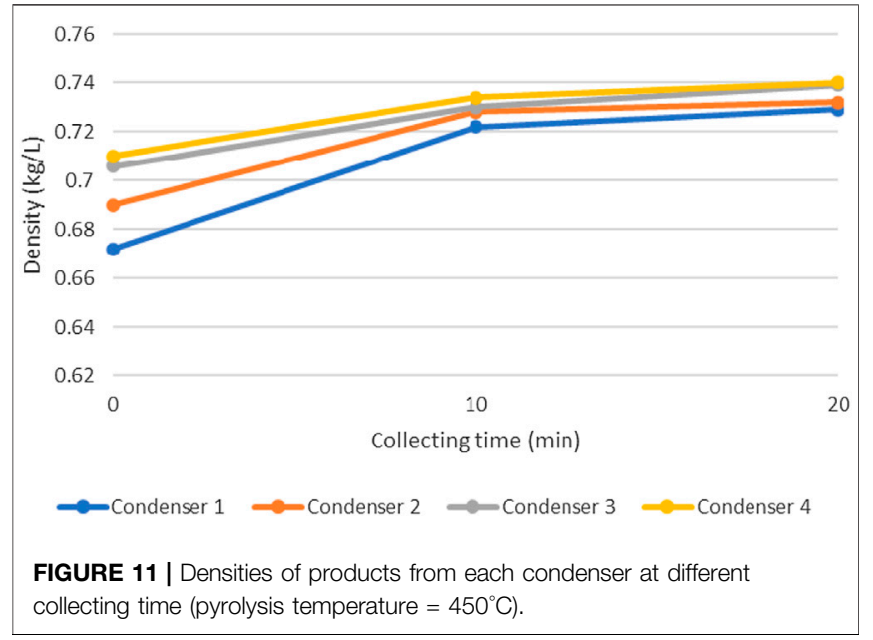

\section{Effect of Pyrolysis Temperature on Product Properties}

The pyrolysis of HDPE at the reactor temperature of 400, 425, and $450^{\circ} \mathrm{C}$ produced oil with the total amount of $22.5,27$, and $40.5 \mathrm{~L}$ per $100 \mathrm{~kg}$ of HDPE, respectively. This shows that $450^{\circ} \mathrm{C}$ is the temperature that produce the highest amount of pyrolysis oil from the experiment. The result corresponds to the study from Kumar and Singh (2013) which reported that the highest liquid yield for HDPE pyrolysis was at $450^{\circ} \mathrm{C}$. Furthermore, pyrolysis oil products were measured for density and viscosity at $40^{\circ} \mathrm{C}$ standard room temperature. It was found that densities of products from the first condenser at the pyrolysis temperature of 400,425 , and $450^{\circ} \mathrm{C}$ were 0.668 , 0.67 , and $0.672 \mathrm{~kg} / \mathrm{L}$, respectively, while viscosities were 3.287 , 3.289 , and $3.297 \mathrm{cSt}$, respectively. It could be seen that density and viscosity increase with the pyrolysis temperature. This is

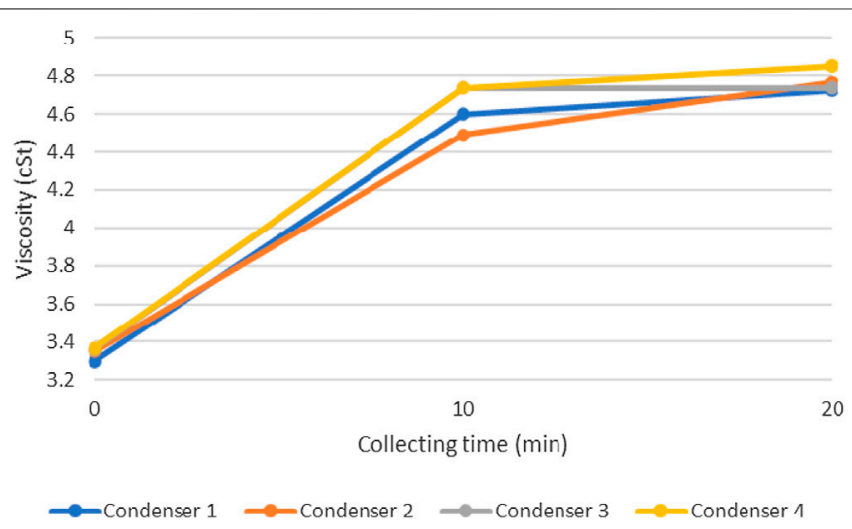

FIGURE 12 | Viscosities of products from each condenser at different collecting time (pyrolysis temperature $=450^{\circ} \mathrm{C}$ ).

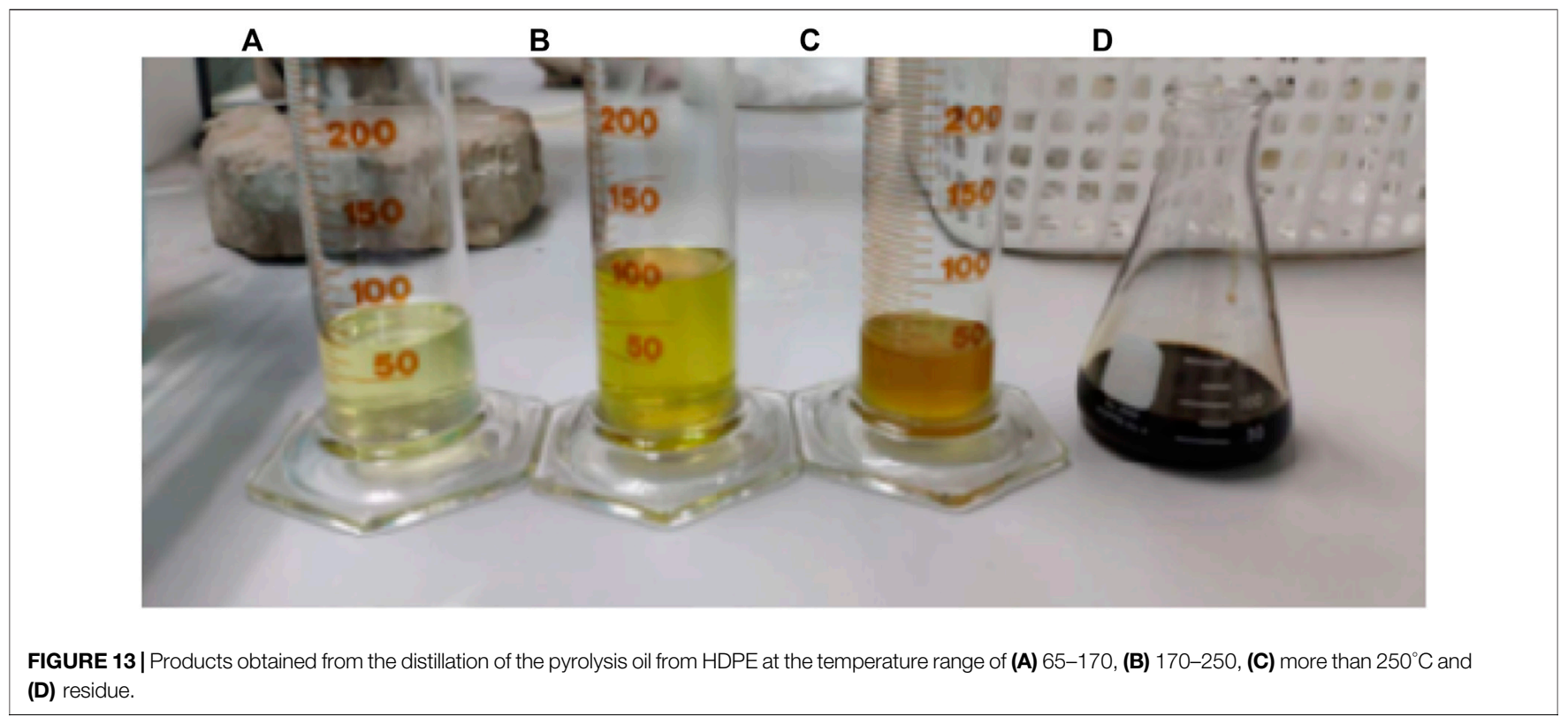




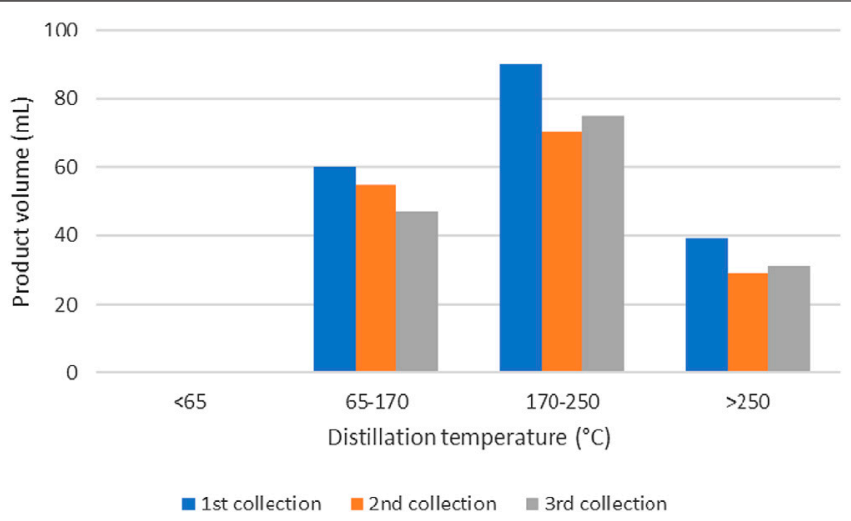

FIGURE 14 | Amount of pyrolysis oil from HDPE at different distillation temperature ranges and different collection periods.

TABLE 1 | Fuel properties compared with standard values.

\begin{tabular}{|c|c|c|c|c|c|c|}
\hline \multirow[t]{2}{*}{ Properties/Fuels } & \multicolumn{2}{|c|}{95 gasoline } & \multicolumn{2}{|c|}{ Kerosene } & \multicolumn{2}{|c|}{ Diesel } \\
\hline & Measured & Standard value & Measured & Standard value & Measured & Standard value \\
\hline Density $\left(40^{\circ} \mathrm{C}, \mathrm{kg} / \mathrm{L}\right)$ & 0.730 & $0.741^{a}$ & 0.800 & $0.807^{\mathrm{a}}$ & 0.814 & $0.837^{\mathrm{a}}$ \\
\hline Viscosity $\left(40^{\circ} \mathrm{C}, \mathrm{cSt}\right)$ & 0.72 & $0.40-0.80^{b}$ & 1.19 & $1.24^{\mathrm{C}}$ & 3.44 & $1.80-4.10^{\mathrm{d}}$ \\
\hline
\end{tabular}

${ }^{a}$ The Energy And Fuel And Data Sheet.

${ }^{b}$ Specific Gravity and Viscosity of Liquids.

${ }^{c}$ Analysis of Adulterant Kerosene in Diesel by Kinematic Viscosity Measurement. (More et al., 2012)

${ }^{d}$ Department of Energy Business, Ministry of Energy.

because higher reaction temperature results in product with longer chain of molecules.

\section{Effect of Collecting Time and Condensers on Product Properties}

Liquid products from the pyrolysis of HDPE were collected from each condenser for three times: 1) when the system reached the target temperature, 2) $10 \mathrm{~min}$ after the first collection, and 3) $20 \mathrm{~min}$ after the first collection. Densities and viscosities of these products were illustrated in Figures $\mathbf{1 1}$ and $\mathbf{1 2}$.

These figures show the density and viscosity of product at the pyrolysis temperature of $450^{\circ} \mathrm{C}$. It could be seen that the density and viscosity of pyrolysis oil increases as the collecting time increases. This is because hydrocarbons with shorter molecular chain could condense earlier than that of the longer chain (Lee and Shin, 2007). Also, the condenser at which the product was collected also affect product properties. Pyrolysis oil tends to have higher density and viscosity as it passes through number of condensers, which is due to the different time of condensation as explained. For other pyrolysis temperatures $\left(400\right.$ and $425^{\circ} \mathrm{C}$ ), product yields were low so that no additional oil could be obtained at the time of the second and third collection periods.

\section{Results of Purification by Distillation}

To improve the purity of liquid products obtained from the pyrolysis of HDPE and PET, simple distillations were conducted at various temperature ranges (Demirbas, 2004). Theoretically, hydrocarbon compounds with $\mathrm{C} 5-\mathrm{C} 7$ (naphtha) would be found at distillation temperature lower than $65^{\circ} \mathrm{C}, \mathrm{C} 6-\mathrm{C} 12$ (gasoline) in the range of $65-170^{\circ} \mathrm{C}, \mathrm{C} 10-\mathrm{C} 14$ (kerosene) in the range of $170-250^{\circ} \mathrm{C}$, and $\mathrm{C} 14-\mathrm{C} 19$ (diesel) would be found above the distillation temperature of $250^{\circ} \mathrm{C}$. Example of products from the distillation were shown in Figure 13 for HDPE as raw material. The amount of pyrolysis oil from HDPE at different distillation temperature ranges and different collection periods was shown in Figure 14.

It could be seen that no product was obtained at the distillation temperature below $65^{\circ} \mathrm{C}$ which could be interpreted that there was no naphtha in this experiment. Kerosene was obtained with highest amount in the temperature range of $170-250^{\circ} \mathrm{C}$, followed by gasoline in the range of $65-170^{\circ} \mathrm{C}$ and diesel at the temperature above $250^{\circ} \mathrm{C}$. Also, the first product collection provided the best distillation yield for all temperature ranges since it gave the highest amount of the distillation product.

\section{Fuel Properties}

Different types of fuel obtained from the pyrolysis process followed by distillation were measured for densities and viscosities. These are compared with their standard values and can be shown in Table $\mathbf{1}$.

It could be seen that densities of pyrolysis fuels were slightly lower than standard values $(0.9-2.7 \%$ difference), while 
viscosities are mostly in range. The result shows the quality of products obtained from the pyrolysis process which were close to conventional fuels. With further refining process, these fuels could certainly be used as an alternative source of energy.

\section{CONCLUSION}

Main product for the pyrolysis of HDPE resin was liquid and PET resin was solid. $450^{\circ} \mathrm{C}$ was the temperature that gives the highest amount of pyrolysis oil in the experiment. The viscosity and density were increased according to three factors: high pyrolysis temperature, the number of condensers and longer collecting time. All refined products in each temperature range had the carbon number according

\section{REFERENCES}

Demirbas, A. (2004). Pyrolysis of municipal plastic wastes for recovery of gasoline-range hydrocarbons. J. Anal. Appl. Pyrol. 72 (1), 97-102. doi:10.1016/j.jaap.2004.03.001

Encinar, J. M., and González, J. F. (2008). Pyrolysis of synthetic polymers and plastic wastes. Kinetic study. Fuel Process. Technol. 89 (7), 678-686. doi:10.1016/j.fuproc.2007.12.011

Kumar, S., and Singh, R. K. (2013). Thermolysis of high-density polyethylene to petroleum products. J. Pet. Eng. 2013, 987568. doi:10.1155/2013/987568

Lee, K.-H., and Shin, D.-H. (2007). Characteristics of liquid product from the pyrolysis of waste plastic mixture at low and high temperatures: influence of lapse time of reaction. Waste Manag. 27 (2), 168-176. doi:10.1016/j.wasman.2005.12.017

More, B. P., Malve, M. K., Toche, R. B., and Shinde, D. B. (2012). Analysis of adulterant kerosene in diesel by kinematic viscosity measurement. Int. J. Pharm. Biol. Sci. 2 (4), 256-261. to their boiling points. The distillation of pyrolysis oil in this experiment provided high amount of kerosene, followed by gasoline and diesel.

\section{DATA AVAILABILITY STATEMENT}

All datasets analyzed for this study are included in the article/ supplementary material.

\section{AUTHOR CONTRIBUTIONS}

All authors listed have made a substantial, direct, and intellectual contribution to the work and approved it for publication.

Williams, P. T., and Slaney, E. (2007). Analysis of products from the pyrolysis and liquefaction of single plastics and waste plastic mixtures. Resour. Conserv. Recycl. 51 (4), 754-769. doi:10.1016/j.resconrec.2006.12.002

Conflict of Interest: The authors declare that the research was conducted in the absence of any commercial or financial relationships that could be construed as a potential conflict of interest.

Copyright (c) 2020 Prurapark, Owjaraen, Saengphrom, Limthongtip and Tongam. This is an open-access article distributed under the terms of the Creative Commons Attribution License (CC BY). The use, distribution or reproduction in other forums is permitted, provided the original author(s) and the copyright owner(s) are credited and that the original publication in this journal is cited, in accordance with accepted academic practice. No use, distribution or reproduction is permitted which does not comply with these terms. 